\title{
XXXII. Observations on maddering; together with a simple and certain process for obtaining, with great beauty and fixity, that colour known under the name of the turkey or adrianople red
}

\section{J.M. Haussmann}

To cite this article: J.M. Haussmann (1802) XXXII. Observations on maddering; together with a simple and certain process for obtaining, with great beauty and fixity, that colour known under the name of the turkey or adrianople red, Philosophical Magazine Series 1, 12:46, 170-175, DOI: $10.1080 / 14786440208676046$

To link to this article: http://dx.doi.org/10.1080/14786440208676046

$$
\text { 曲 Published online: } 18 \text { May } 2009 .
$$

Submit your article to this journal ए

\section{Article views: 4}

View related articles $\asymp$ 
XXXII. Obfervations on Maddering; together with a fimple and cerlain Process for obtaining, with great Beauty and Fixity, that Colour known under the name of the Turkey or Adrianople Red. By J. M. Ha Us M A N N*.

T

HAVE already indicated, in the Annales de Cbimiet and the Journal de F'byfrque, that earths and metallic oxides have more or lefs the property of attracting and retaining the colouring parts of vegetable and animal fubftances; alumine and the oxide of iron poffefs it in a greater degree than the oxide of tin; but the attractive force of the latter far furpaffes that of the other earths and metallic oxides in regard to the colouring parts of the faid fubitances.

Alumine and metallic oxides do not retain, with the fame force of adhefion, the colouring parts of all animal and vegetable fubitances indifcriminately; that of madder adheres much ftronger than thofe of the other colouring fubftances, which may be claffed in the following order: kermes, cochineal, logwood, yellow India wood, woad, quercitron, Brazil wood, red India wood, yellow berries, 8xc. The gallnut, thumac, and other aftringent colouring fubftances, act principally by means of the gallic acid, and, in regard to their degree of fixity, may be plared immediately after madder : the cafe is not tibe fame with the Pruffic acid, which communicates a colour to different metallic oxides, from which it can be feparated cold by alkaline leys.

To judge of the fixity of colours arifing from animal and vegetable fubitances, the beft method is to employ a ley of oxygenated muriate of potafh or foda, with excefs of alkaline carbonate. The longer or fhorter refittance which the colours make in this ley, will indicate what they will make when acid, alkaline, faponaceous, and other reagents are employed.

In the art of dyeing, and that of cotton-printing, the name of maddering is given to that procefs by which the colouring parts of madder are transferred, by means of water with the aid of heat, to alumine, or to the oxide of iron fixed in any kind of ftuff.

* From the Anrales de Cbimie, No. 122.

+ We muft here mention, that $C$. Chaptal, minifter of the interior, 2 gond judge in matters of this kind, when he cummunicated to us thefe obfervations, wrote as follows: " C. Hauffmann, manufacturer of printed cottons at Laglebach, near' Colmar, in thie department of the Upper Rhine, well known among thof chemifts who apply the difcoveries of fience to improvements in the arts, tranfmitted to me the anuexed memoir. In my opinion it will be of nility to make it known in your Annals, and the author on my requeft has coniented to its bing publifhed." Note of the Editors of tibe Annales de Chimie.

The 
The brightnefs and fixity of the colours obtained from maddering depend not only on the procefs, but alfo on the ftate and purity of the water as well as of the madder. It is therefore abfolutely neceffary to avoid or to render inactive every acid, alkaline or faline fubftance that may be contained in the water, or in the madder itfelf. I have fhown that, by adding carbonate of lime, (pounded chalk,) madder which I fufpected to contain gallic acid was corrected; but that my friend Charles Bertholdi, profeffor in the central fchool of the Upper Rhine, afterwards found that it was fulphuric acid united to magnefia.

The important difcovery of this addition of chalk, which I made twenty-five years ago, has given birth to many manufactories, and improved all thofe eftablithed near waters which do not run over or hold in folution this earthy falt, without which it is abfolutely impoffible to obtain beautiful and fixed madder colours. This chalk fince that time has become a new object of commerce; and as the price is very moderate, $I$ have not yet determined the juft proportion to be employed: in general, I take one part for four, five, or fix, of madder.

In order to obtain the brighteft madder colours, it is not fufficient to attend to the quality of the water and of the madder: it is neceffary alfo to obferve the degree of the heat of the bath : a low temperature will check the attraction of the colouring parts, and prevent them from being extracted, while one too high will favour the adhefion of the yellow particles of the madder, which obfcure and tarnifh the fhades intended to be produced. The only colour which gains by increafing the heat is black. I have always obferved, that on withdrawing the fire from below the boilers, when the hand can no longer be held in the aqueous vehicle which they contain, if the maddering be then continued for two or three hours, the moft fatisfactory refults will be obtained, as the furnace ftill retains a fufficient quantity of heat to maintain the vehicle at the fame temperature, efpecially when, according to cuftom, large boilers are employed. Befides, it would be very difficult to fix a determinate degree of heat by the thermometer when the furnaces are large.

The yellow parts of the madder as well as of other colouring fubftances are, it is probable, nothing elfe than the colouring parts themfelves combined with oxygen. The product of this combination, by acquiring greater folubility, fuffers itfelf with more difficulty to be taken away by clearing, if the heat has not been properly regulated during the procefs of dyeing. I have uften obferved that madder and other co. 
louring fubftances, when long expofed to the atmofpheric air, do not give colours of the fame intenfity and the fame brightnefs as before; either becaufe thefe fubftances abforb the oxygen of the atmofphere, or that they procure this radical from the water which they attract, or which they naturally contain as a conftituent principle, and which is decompofed by a flow and infenfible fermentation. The expofure, on the grafs, of cotton or linen dyed a dark madder red, might fupport the idea of a change to a reddifh yellow; for this dark colour becomes clearer but fainter by the expofure, and then affumes a more agreeable thade of crimfon. I have thown, in a memoir on indigo, inferted in the Journal de Pby/zque for the year 1788 , that nitric acid changes this blue fecula into a yellowith fubftance: a fimilar change takes place by expofing, on the meadow, the fame fecula fixed on any ftuff whatever; and the yellow refulting in thefe two ways is more foluble in warm water than in the fame liquid when cold. It however appears that the combination of oxygen is not the only caufe of the change of colours, fince curtains of any ftuff dyed or coloured any thade whatever by vegetable or animal fubftances, and expofed to the light, lofe their colour entirely in the courfe of time on the fide expofed to the folar rays, while the oppofite fide retains it for a confiderable time. If the rays of the fun then give more vigour to living bodies of the animal and vegetable kingdom by difengaging from the latter oxygen gas, it appears that they act with deftructive influence on the fame bodies deprived of life; by decompofing their conftituent principles. In all cafes it will be proper to preferve the colouring ingredients in dry places fheltered from the light, which acts upon thefe bodies perhaps only by decompofing the conftituent aqueous part, the oxygen of which may join the carbon to form carbonic acid. Refinous and oily fubftances fhould be preferved in the fame way. Thefe conjectures prove at leaft that the action of the fun's rays, or of light, on thefe bodies, in general prefents a vaft field for interelting experiments to be undertaken.

If in maddering brighter colours are obtained by carefully regulating the beat, a facrifice is made at the fame time of a fmall portion of the colouring parts of the madder, which cannot be entirely exhaufed except by then increafing the heat to ebullition; but as the colours thus obtained are degraded more or lefs in the ratio of the quantity of the madder, the gall-nut or thumac ufed, this method mutt be employed with caution, and principally for common effects, either in regard to cotton or linen. To avoid as much as poffible the lofs of madder after the maddering of good arti- 
cles has been terminated, and before the common ones are put into the boiler, powdered gall-nut or fhumac muft be added, with a new but fmall portion of madder: the procefs muft be managed alfo in fuch a manner, that the ebullition Thall not take place till two hours after.

I feveral times tried to exhauft the niadder by fimple ebullition, and without adding any thing elfe than chalk; but I found that this was unfavourable to all colours, black excepted : it even appeared that the effect of the madder was much Iefs than when the heat was moderately applied, and when the accumulated caloric eafily decompofed the colouring fubftance. It is this tendency to be decompofed, and particularly by fermentation, however little it be moiftened or diluted with water, which has hitherto prevented me from obtaining a fubftantial colour, pretty dark, and fufficiently fixed to be applied on any kind of ftuff. I obferved alfo, that if the heat was carried too far the firft time, in circumitances when it was propofed to madder a fecond and third time, it prevented me not only from obtaining bright and agreeable fhades, but alfo of the requifite intenfity. The aqueous rehicle of the madder, at too high a temperature, never fails to weaken the adhefive force of the alumine and the oxide of iron to the ftuff, and to take from it a portion, which an experienced eye may eafily remark on examining the bath.

I hall here repeat; that for common and low-priced articles it is indifpenfably neceffary to employ gall-nuts or humac, which will fave one half and even two thirds of the madder; but the colours obtained are neither fo fixed nor fo bright. The addition of chalk, however, mult not be omitted; otherwife the gallic acid will carry away a portion of the alumine and coloured oxide of iron, which will weaken the rhades, and, by tarnifhing the ftuffs, will alfo altack the white which may have been preferved in them. Without the addition of gall-nuts or fhumac, it feemed to me impoffible to exhaufe the madder entirely of its colouring parts; which made me prefume that their adhefion is favoured by the vifcid nature of the tanning principle of thefe aftringent fubitances, which carry away and combine with themfelves the colouring parts. I thall obferve alfo, that gall-nuts as well as thumac lofe the property of dyeing black; and acquire, on the other hand, that of dyeing or colouring alumine yellow, oxide of iron olive green, by the addition of chalk, the calcareous bafe of which unites itfelf to the gallic acid. Do thefe yellow and olive-green colours arife from any peculiar fubftance contained in the gall-nuts and thumas, or are they indebted for 
their origin to the tanning principle? This remains to be examined.

The quantity of madder to be employed in dyeing ought not only to be proportioned to the extent of the furfaces to be maddered, but alfo to the concentration of the liquors of the acetite of alumine and iron, improperly called mordants; that is to fay, to the greater or lefs quantity of alumine and oxide of iron which thefe faline liquors, either infulated or mixed together, when they dry on the articles to be dyed, may have left or depofited there by the evaporation of the acetic acid. If the objects to be dyed are not numerous, and, in particular, when bright thades only are to be produced, they may be maddered only once; but when they are numerous, and intended to have dark thades, the maddering muft be repeated twice, and even thrice. Three quarters of a pound of madder of a good quality are fufficient for dyeing a piece of white Indian cloth of ten ells in length and three quarters broad, intended to exhibit only a few coloured objects : the quantity of the colouring fubftance muft be increafed in the ratio of the mafs of alumine and oxide of iron, fixed on a piece of ftuff of the above dimenfions. It may be extended to 6,8 , 10, and even 12 pounds, for a ground well covered with a lively and very intenfe colour. Intelligence and practice in the management of a dye-houfe will not fail to indicate nedrly the proper proportions.

Whatever care may be employed in maddering to avoid the adhefion of the yellow parts, the colours obtained will be far from having all the beauty, and fixity which they might acquire by clearing, preceded by very long ebullition in exceedingly pure water. This ebullition alone, by the addition of bran, will ferve to brighten the colour: more rofy reds will be obtained by employing foap with or without the addition of bran; carbonate of potanh or of foda, fubftituted for bran, will make the reds incline to crimfon; but I muft obferve, that unlefs the workman choofes to run the rifk of making the reds entirely brown, and in fuch a manner that it will not be poffible to reftore them, it will be neceffary, before foap and alkalies are applied to the ftuffs, to expofe them to the action of the ftrongelt heat that can be communicated to water. This operation will be attended with fuccefs, if as little paffage as poffible be afforded to the fteam, and if the boilers employed be converted into a fort of digefters. The fixity of the colours will be proportioned to the time employed in expofing them to the action of the boiling water. It is needlefs to obferve, that there is no 
danget of fpoiling the colours by foap and alkaline carbonates, when tile maddering, inftead of being directed with a moderate heat, has been carried to ebullition, as is practifed in many dye-houfes; but, in this cafe, the colours obtained are more difficult to be cleared.

As water charged with oxygenated muriatic acid eafly carries away the colouring parts of madder, as well as other vegetable and animal fubitances, by decompofing them; and as acids more concentrated may, in their turn, take from the Atuffs the colourlefs alumine and the oxide of iron, it is impoffible for me to adopt the idea of a chemical combination of the colouring parts with alumine and metallic oxides, which, in my opinion, when fixed and coloured on any ftuff, form only compound aggregates.

The clearing of objects printed on a white ground requires modifications, which I thall detail on a future occafion, when I find leifure. It will therefore be fufficient at prefent to ftate, that after continuing for fome time my experiments on the Turkey red, inferted in the Annales de Cbimie for the year I792. I at laft found a red much more beautiful and durable than that of the Levant, by fixing alumine on cotton, thread, and linen, by an alkaline folution of this earth mixed with linfeed oil. The following is the procefs I employed.

[To be continued.]

XXXIII. Notices refpecting New Books.

Ausfibrliche Gefcbicbte der Theoretifcb Praktifcben Ulbrmacberkunft, \&c. A Hiftory of Clock- and Watch-making, both Theoretical and Practical, fince the earlief Method of dividing the Day to the End of the I 8 th Century. By I. H. Moriz POPPE, i8oi. 8vo, 564. p. 8.

T

HE author of this work having publifhed, in $1797, \mathrm{An}$ Effay towards a Hiftory of the Origin and Progrels of Clockand Watch-making, confitting of fix fhetts; it met with fuch a favourable reception, that he was induced to improve and enlarge it to its prefent fize. He acknowledges the obligations he is under to profeffors Kaftner and Beckmann, who affitted him with their advice and information; and who, on account of their learning and extenfive reading, were able to fupply him with much ufeful information. The whole work is divided into ten chapters.

I. The oldeft method of dividing the day, and the invention of fun-dials.-The period when fun-dials werc invented is as 